\title{
Post-donation variations in various hematological parameters, serum ferritin and Hba1c level in diabetic and non-diabetic donors: A study report
}

\author{
Chhita Ranjan Prasad ${ }^{1}$, Deepak Kumar Dasmohapatra ${ }^{2}$, Anuradha Panda ${ }^{3}$, Kailash Agrawal ${ }^{4}$ \\ ${ }^{1,4} \mathrm{HOD},{ }^{1,3} \mathrm{PG}$ Student, ${ }^{1}$ Dept. of General Medicine, ${ }^{2-4}$ Dept. of Pathology, Veer Surendra Sai Medical College and Research, \\ Burla, Odisha, India \\ *Corresponding Author: \\ Email:dkdm@rediffmail.com
}

Received: $14^{\text {th }}$ November, 2017

Accepted: $16^{\text {th }}$ December, 2017

\begin{abstract}
Introduction: Whole blood donation is almost obsolete in developed country but still it's the main stay of transfusion practice in developing countries. Iron deficiency is a complication of regular blood donation.

Objective: To study the various hematological parameters along with serum ferritin \& HBA1C level in non-diabetic and diabetic blood donor population.

Materials and Methods: Complete blood count was performed using six part analyser, serum ferritin using ELISA and HBA1C using HPLC method.

Results: In our study there was a decrease in level of some of the hematological parameters, serum ferritin and HBA1C level after donation.

Conclusion: From our study we conclude that only hemoglobin estimation in blood donors is not sufficient for acceptance of donations and serum ferritin level should be measured in regular blood donors. For diabetic donors on oral medication at least HBA1C level should be repeated after two months of donation.
\end{abstract}

Keywords: Iron deficiency, Blood donation, Hematological parameters, Serum Ferritin, HBA1C level.

\section{Introduction}

Voluntary blood donation is an excellent humanitarian service towards mankind. Till date suitable replacement of blood is yet to be discovered. Transfusion service relies on blood donation.

Our current system emphasizes primarily on screening of donors and protection against Transfusion Transmitted Infections. A little is being done for study regarding health of blood donors. It is well known that there will be a significant reduction of $\mathrm{Hb} \%$ and Iron after a unit of blood donation. With increasing demands of blood, the spectrum of blood donors too is increasing but disproportionate to demand. ${ }^{1}$ Now healthy diabetics on oral medication also constitute a minor pool of blood donors. Approximately one tenth of the blood volume is drawn from the blood donors, leading to loss of one tenth of preformed $\mathrm{HbAlc}$.

The bone marrow will compensate the blood loss by an increased erythropoiesis, resulting in relatively younger pool of erythrocytes which is devoid of HbA1c. As glycelation of hemoglobin is a slow process, ${ }^{2}$ the increased synthesis of erythrocytes will therefore, result in a drop of HbAlc. Previous researches also suggested that blood loss and whole blood donation can affect $\mathrm{HbA} 1 \mathrm{c}$ level. ${ }^{3,4}$

In India, majority of blood banks use $\mathrm{Hb} \%$ parameter (male $>12.5 \mathrm{gm} / \mathrm{dl} \&$ female $>11.5 \mathrm{gm} / \mathrm{dl}$ ) as cut off value according to WHO guidelines for blood donation. ${ }^{1}$ This parameter is a poor indicator in the measurement of body iron store as $\mathrm{Hb} \%$ can be normal in a person though there may be significant depletion of iron stores. In studies it has been cleared that at least three months is required to replenish body iron stores. ${ }^{5}$ An accurate diagnosis of iron deficiency requires several laboratory tests including measurements of serum ferritin concentrations and red cell indices such as mean cell volume (MCV), mean corpuscular hemoglobin $(\mathrm{MCH})$ and mean corpuscular hemoglobin concentration (MCHC). ${ }^{6}$ From previous studies it is known that serum ferritin level will decrease after each donation and regular blood donors are at a danger of developing anemia particularly females are more vulnerable.

\section{Materials and Methods}

Our study was conducted in department of transfusion medicine in association with department of Pathology in Veer Surendra Sai Medical College and Research, Burla.

A total 104 numbers of voluntary blood donor samples were collected from September 2016 to March 2017 , out of which sixteen number of donors were diabetic.

These samples were tested for various tests including complete blood count, evaluation of iron status and HBA1C status of blood donors.

All donors were evaluated as per guidelines. Each donor donated about $350 \mathrm{ml}$ of whole blood. Predonation blood was collected in a $3 \mathrm{ml}$ of EDTA vial for assay of $\mathrm{CBC}$ and HBA1C. A $3 \mathrm{ml}$ of plain tube was used for measurement of serum ferritin. After- 
donation again the same amount of blood was collected after two hours. All donors were given the same amount of food and drinks after donation. Complete blood count was performed using a complete blood count analyser machine, serum ferritin by ELISA and HBA1C using HPLC method. All Blood Samples were analysed within 24 hour following collection.

Data was analysed using excel sheet and statistical computer software. Serum ferritin value below $15 \mu \mathrm{g} / \mathrm{L}$ was considered iron deficient, $15-20 \mu \mathrm{g} / \mathrm{L}$ as borderline and above $20 \mu \mathrm{g} / \mathrm{L}$ as normal. Hemoglobin percentage below $12.5 \mathrm{gm} / \mathrm{dl}$ and $11.5 \mathrm{gm} / \mathrm{dl}$ was considered to represent anemia in male and females respectively. Glycelated hemoglobin levels below $5.7 \%$ was taken as normal, between $5.7 \%$ to $6.4 \%$ as pre-diabetics, more than $6.5 \%$ were considered as diabetics.

\section{Results}

Out of total 104 numbers of volunteer, 88 were non-diabetics and 16 were diabetics. All the nondiabetic volunteers were having normal hematological parameters. All diabetic donors were on oral medications having a good glycemic control and were not on insulin treatment as per guideline. The donors were between 18 to 58 years of age, majority of them were between 18 to 30 years.

Showing mean value of Haematological parameters of both non-diabetic and diabetic donors before donation and decrease in haematological parameters after donation in brackets $(\mathrm{P}$ value $<0.05$ is significant.).

Table 1:

\begin{tabular}{|l|c|c|c|}
\hline Parameters & Non-diabetic & Diabetic & P value \\
\hline AGE Gr. & 42.3 & 55.7 & \\
\hline HB\% & $13.6(1.28)$ & $13.3(1.19)$ & $<0.05$ \\
\hline BMI & 27.1 & 28.9 & \\
\hline MCV & $89.23(7.23)$ & $87.35(6.83)$ & $<0.001$ \\
\hline MCH & $29.57(2.82)$ & $29.28(2.91)$ & $<0.001$ \\
\hline MCHC & $35.43(2.13)$ & $34.86(2.01)$ & $<0.001$ \\
\hline Serum Ferritin & $92.13(31.83)$ & $73.17(34.16)$ & $<0.001$ \\
\hline HBA1C & $5.7(0.42)$ & $6.9(0.83)$ & $<0.05$ \\
\hline
\end{tabular}

Following blood donation HBA1C level of both diabetic and non-diabetic donors showed reduction.
This graph represent the variations of HBA1C level within eight weeks after donation in our set-up.

\section{Graph 1:}

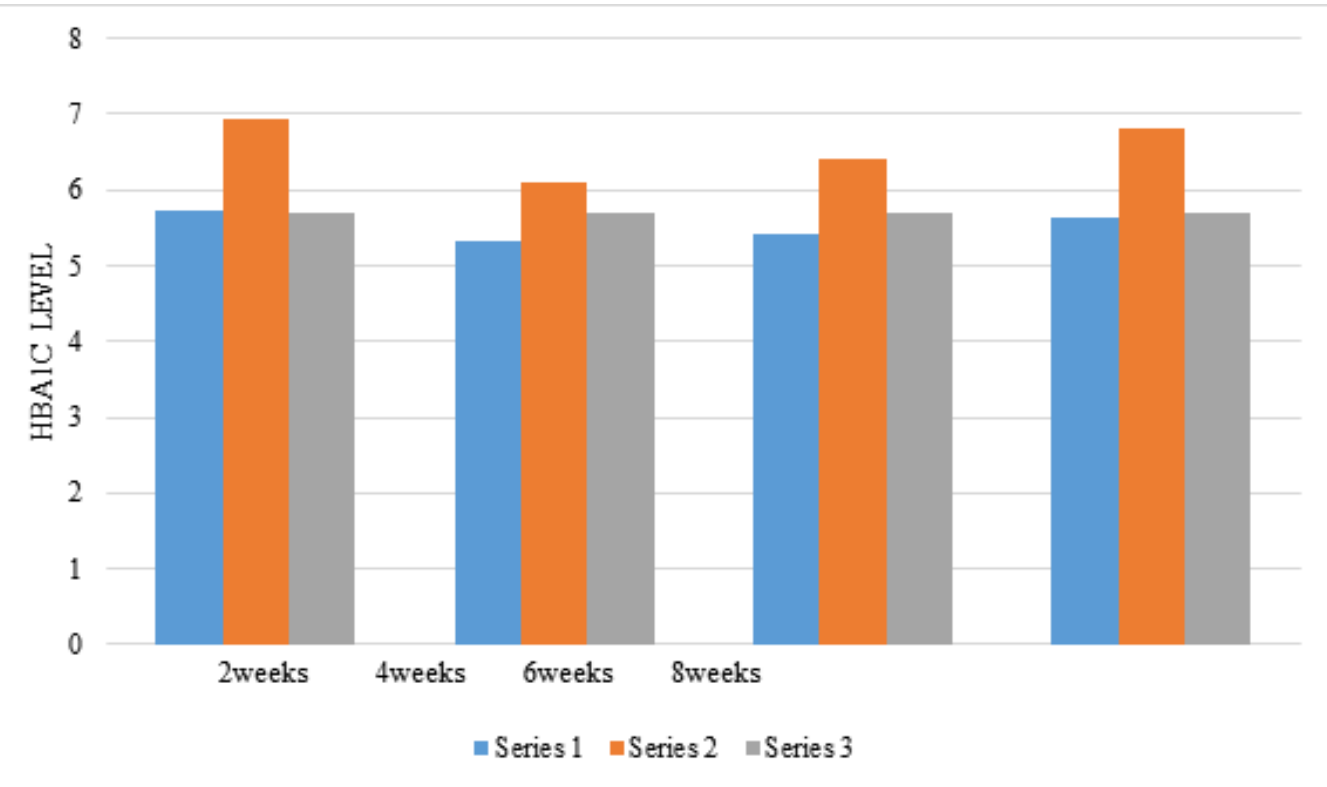

Series 1: Non-diabetic donors, Series 2- Diabetic donors, Series 3- Normal HBA1C value.

Comparison done at two, four, six and eight weeks interval. 
Showing variation between mean decrease in serum ferritin level of both non-diabetic and diabetic donors post donation up to eight weeks.

\section{Graph 2:}

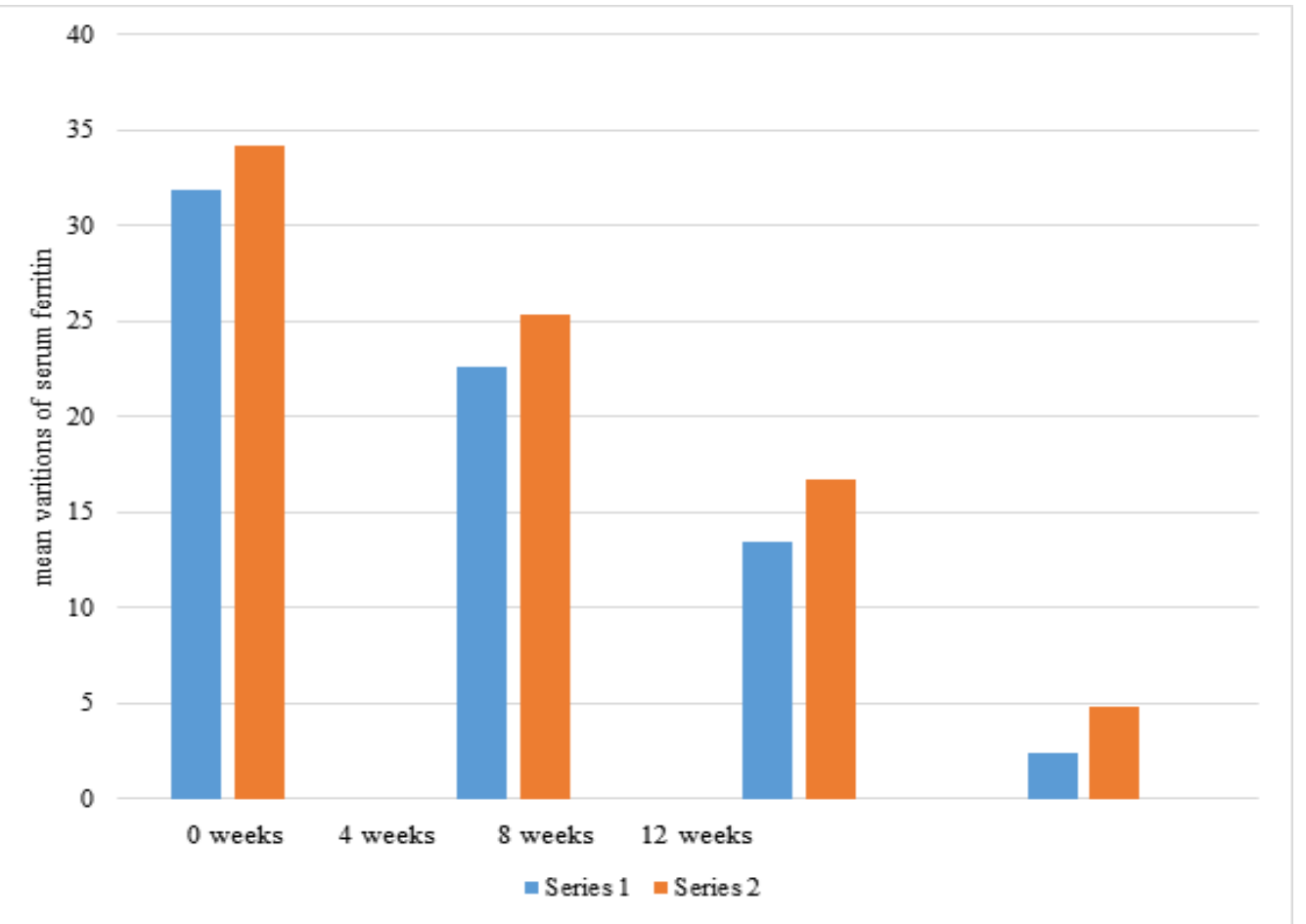

Series-1: Non-Diabetic donors, Series-2: Diabetic donors

\section{Discussions}

There are many studies which shows iron depletion after blood donation. In case of healthy diabetic donors on oral medication a very few studies regarding HBA1C status post-donation has been done. National blood transfusion council and blood banks should have the responsibility to protect the well-being of donors. With continuous rise in demand for blood, recruiting sufficient numbers of new blood donors is a big challenge in developing countries as many of them do not meet required $\mathrm{HB} \%$ criteria. ${ }^{7}$ At present the blood donors are at risk of Iron store depletion which may increase with increasing frequency of blood donation.

Shalini bahadur et.al in their study had shown the extent of iron deficiency in our healthy blood donor population, female donors are being more vulnerable. ${ }^{8}$ Toby L. Simon et.al recommended iron supplementations in menstruating female donors. ${ }^{9}$ Our national blood donation programme doesn't include evaluation of iron stores in blood donor population.

Alverz-ossorio et al recommend measurements of serum ferritin levels after five donations. ${ }^{10}$ This will help to identify iron deficient donors at risk of becoming anemic.

Magnussan et.al in a study proposed for providing standard dose of iron supplementation to reduce the chances of anemia in donor population. ${ }^{11}$ Radtke et al recommended for low dose of iron therapy (20 $\mathrm{mg}$ per day) which has been found to be effective in management of iron deficiency in blood donors thus reducing the rate of donor deferral for low haemoglobin. ${ }^{12}$

Early detection of iron deficiency among blood donors would allow appropriate readjustment of donation intervals and would guide the use of iron supplementation. Though blood donor's population can effectively absorb iron in comparision to the normal non-donor individuals, but still repeated blood donation leads to depletion of iron stores resulting in deferral of donors. ${ }^{13}$ For diagnosis of IDA, plasma ferritin threshold of $15 \mu \mathrm{g} / 1$ was used in this study, as suggested by clark. ${ }^{14}$

Blood donors having Diabetes (Type 2) are at risk of falsely lowered HBA1C levels leading to wrong interpretation. Angelique Dijkstra et al in his study suggested a marked reduction of $\mathrm{HbA} 1 \mathrm{c}$ for at least two months after whole blood donation. ${ }^{15}$ In our study we found a significant decrease in HBA1C level in almost $>50 \%$ of blood donors including both healthy and diabetic blood donors on oral medication.

Screening of the donors for serum ferritin levels at the time of first donation and subsequently once every year seems rational for voluntary blood donation programme to avoid iron deficiency in donor population. Our blood donation programmes and blood banks should take initiative to educate the donors to 
reduce the magnitude of iron deficiency in our donor population.

\section{Conclusion}

Currently routine implementation of testing the serum ferritin level in blood donors is not being yet adopted by blood banks. Blood donation has a profound influence on level of serum ferritin and HBA1C level.

Hence, we suggest for reviewing the current guideline $(\mathrm{Hb} \%>12.5 \%)$ for blood donation of a donor. It seems logical to include serum ferritin measurement in assessment of donor iron store which will decrease the chances of conversion of healthy donors to anemic. The insignificant decrease in various haematological parameters needs further evaluation. In case of healthy diabetic donors on oral medications, we recommend that at least HBA1C level should be repeated after two months of donations.

\section{Acknowledgement: None \\ Conflict of Interest: None}

Abbrevations used: Hb: Hemoglobin; MCV: Mean corpuscular volume; $\mathrm{MCH}$ : Mean corpuscular hemoglobin; MCHC: Mean Corpuscular Hemoglobin Concentration; EDTA: Ethylene-diamine-tetra acetic acid; IDA: Iron deficiency anemia; CBC: Complete Blood Count; HbA1c: Hemoglobin A1c (Glycelated hemoglobin).

\section{References}

1. Ali AM, Mc Avoy AT, Ali MA, et al. An approach to determine objectively minimum hemoglobin standards for blood donors. Transfusion.1985;25(3):2868.https://doi.org/10.1046/j.15372995.1985.25385219919.x PMid:4002317.

2. Bunn HF, Haney DN, Kamin S, Gabbay KH, Gallop PM. The biosynthesis of human hemoglobin A1c. Slow glycosylation of hemoglobin in vivo. J Clin Invest.1976;57:1652-9. doi:10.1172/JCI108436 PMid: 932199.

3. Starkman HS, Wacks M, Soeldner JS, Kim A. Effect of acute blood loss on glycosylated hemoglobin determinations in normal subjects. Diabetes Care 1983;6:291-4. PMid:6872811.

4. Borai A, Livingstone C, Farzal A, Baljoon D, Al Sofyani $\mathrm{A}, \mathrm{Bahijri} \mathrm{S}$, et al. Changes in metabolic indices in response to whole blood donation in male subjects with normal glucose tolerance. Clin Biochem. 2016;49:51-6. doi:10.1016/j.clinbiochem.2015.08.023 PMid:26320016.

5. Torben Pottgiesser, Wolfgang Specker, Markus Umhau, Hans-Hermann Dickhuth, Kai Roecker, Yorck O. Schumacher. Recovery of hemoglobin mass after blood donation. Transfusion. 2008;48:1390-1397. doi:10.1111/j.1537-2995.2008.01719.x.

6. Hemali Jayantilal Tailor, Prashant Ramanbhai Patel, Amrish Kumar Narhari Prasad Pandya, Sarita Mangukiya. Study of Various Hematological Parameters and Iron Status among Voluntary Blood Donors. Int J
Med. Public Health. 2017;7(1):61-65. doi:10.5530/ijmedph.2017.1.11.

7. Simon TL. Iron, iron everywhere but not enough to donate. Transfusion 2002;42(6):664-5.

https://doi.org/10.1046/j.15372995.2002.00121.x;PMid:12147015.

8. Shalini Bahadur, Meenu Pujarini, Manjula Jain. Donor deferral due to anemia: A tertiary care center based study. Asian J. Transfusion sci.2011;5(1):53-55. doi:10.4103/0973-6247.76001.

9. Toby L. Simon, MD; Philip J. Garry, PhD; Elizabeth M. Hooper. Iron Stores in Blood Donors. JAMA. 1981;245(20):2038-2043. doi:10.1001/jama.1981.03310450030018.

10. Alvarez-Ossorio L, Kirchner H, Kluter H, Schlenke P. Low ferritin levels indicate the need for iron supplementation: strategy to minimize iron-depletion in regular blood donors. Transfusion Med. 2000;10(2):10712.https://doi.org/10.1046/j.1365-3148.2000.00239.x.

11. Magnussen K, Bork N, Asmussen L. The effect of a standardized protocol for iron supplementation to blood donors low in hemoglobin concentration.Transfusion.2008;48:749-54.doi: 10.1111/j.1537-2995.2007.01601.x.

12. Hartmut Radtke, Joanna Tegtmeier, Lothar Röcker, Abdulgabar Salama, Holger Kiesewetter. Daily doses of $20 \mathrm{mg}$ of elemental iron compensate for iron loss in regular blood donors: a randomized, double-blind, placebo-controlled study. Transfusion 2004;44:14271432.doi: 10.1111/j.1537-2995.2004.04074.x.

13. Gary M. Brittenham. Iron deficiency in whole blood donors. Transfusion. 2011;51(3):458461.doi:10.1111/j.1537-2995.2011.03062.x.PMcid: PMC307856119.

14. Clark SF. Iron Deficiency Anemia. Nutrition in Clinical Practice 2008;23:128-

41.https://doi.org/10.1177/0884533608314536; PMid:18390780.

15. Dijkstra A, Lenters-Westra E, de Kort W, Bokhorst AG, Bilo HJG, Slingerland RJ, et al. (2017) Whole Blood Donation Affects the Interpretation of Hemoglobin A1c. PLOS ONE.12(1): e0170802.doi:10.1371/journal.pone.0170802. 